\title{
A Model Simulation for Decreased Left Ventricular Stroke Volume in Obstructive Sleep-Disordered Breathing
}

\author{
Ernesto Goldman \\ Department of Anesthesiology, Wexner Medical Center at The Ohio State University, 410 W. 10th Avenue, Columbus, \\ $\mathrm{OH} 43210$, USA \\ Correspondence should be addressed to Ernesto Goldman, ernesto.goldman@osumc.edu
}

Received 18 August 2012; Accepted 27 September 2012

Academic Editors: P. Von Wichert and C. C. Witt

Copyright (c) 2012 Ernesto Goldman. This is an open access article distributed under the Creative Commons Attribution License, which permits unrestricted use, distribution, and reproduction in any medium, provided the original work is properly cited.

Background. Increased negative intrathoracic pressures are recognized to exacerbate left ventricular dysfunction in obstructive sleep-disordered breathing. Reportedly left ventricular stroke volume (LVSV) decline appeared greater than predicted by the obstruction alone. Objectives. Whether this effect is more dependent on biventricular elasticity and fluid shifts than on breathing-related transmural pressures could be inferred from a mathematical model simulation. Design. A previously validated cardiopulmonary model in healthy subjects during inspiratory loading was modified by parameter adjustments to fit its ventricular volumes output to published clinical data of decreased LVSV in obstructed breathing. Results. Reduced left ventricular enddiastolic compliance and increased central blood volume from baseline each simulated a $20 \%$ drop in LVSV whereas twice as much change was the result of increasing a mere $400 \mathrm{~mL}$ to the unstressed volume of systemic veins. An intermediate value was obtained by decreasing right ventricular end-diastolic compliance and higher systemic venous compliance. Conclusions. Simulations encompassing a wide range of decreased stroke volume at comparable intrathoracic pressures suggested a prominent role of decreased myocardial distensibility (possibly coupled to fluid migration) in the stroke volume fall.

\section{Introduction}

Obstructive sleep-disordered breathing (OSB) is associated with cardiovascular comorbidities (hypertension, increased afterload, sympathetic outflow, heart failure, left ventricular (LV) dysfunction, cyclical increases in LV wall tension, increased venous return) with variable decreases in LV stroke volume (LVSV) measured mostly around $30 \mathrm{cmH}_{2} \mathrm{O}$ of negative intrathoracic pressure (Pth) [1-16].

However, only a fraction of the magnitude of these LVSV drop was depicted by a mathematical model simulation [17], validated with the inspiratory fall in arterial pressure during spontaneous breathing at increased inspiratory loading in normal subjects over a wider Pth range (up to $-52 \mathrm{mmHg}$ ).

Thus, although increased negative Pth in OSB (with concomitant increased LV afterload by higher LV transmural intracavitary pressure and reduced LV preload by interdependence) is recognized as an independent pathophysiological mechanism, it partially explains the larger LVSV reduction in OSB patients when compared to that simulated by inspiratory loading. Here the model simulation further explores this discrepancy by assessing the potential role of LV rigidity, end-diastolic, and end-systolic LV volumes and volume overload at different levels of airway resistance.

\section{Methods}

Cardiopulmonary simulations were performed in MATLAB (R2011b) using an open-source, validated forward-model [18-20], capable to generate acceptable human pulsatile hemodynamic waveforms, cardiac output and venous return curves and beat-by-beat variability over short time periods and stable experimental conditions. Full description of the model components and its parameters as a function of airway resistance was previously reported [17]. Simulations strongly correlated with the inspiratory fall in arterial pressure during increased inspiratory resistance breathing in humans. Airway obstruction simulation data were obtained at each of 13-step increments in airway resistance from 


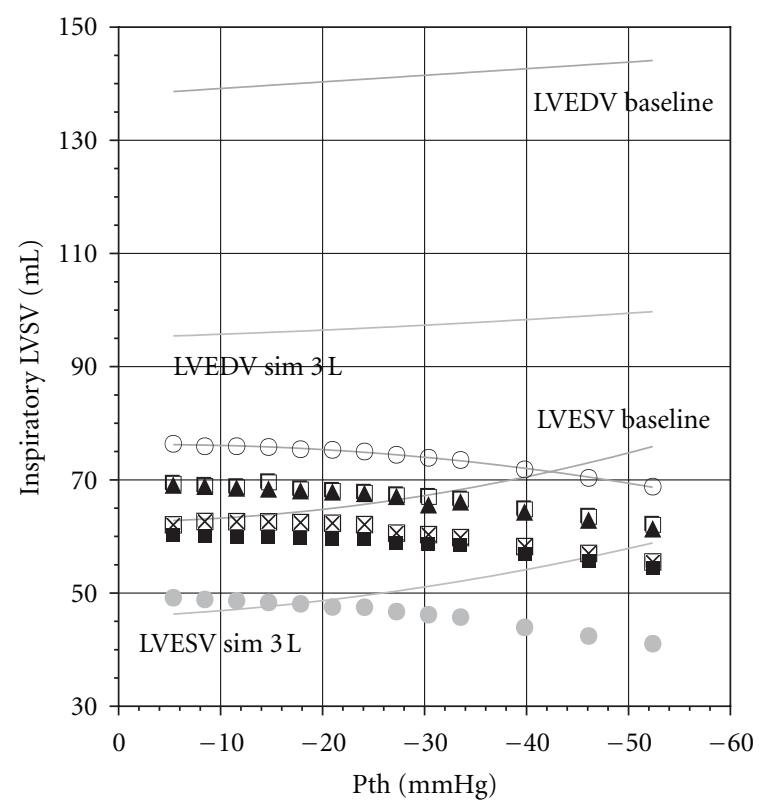

FIGURE 1: Simulations of the inspiratory left ventricular stroke volume (LVSV)-intrathoracic pressure (Pth) relationships showed the steady LVSV decline with airway resistance and the parallel displacement from baseline by parameter modifications: decreased left ventricular end-diastolic compliance (open square), increased central blood volume (closed triangle), decreased right ventricular end-diastolic compliance (crossed square), increased systemic veins compliance (closed square), and increased $400 \mathrm{~mL}$ of the unstressed volume of systemic veins (to $3 \mathrm{~L}$, gray closed circle). The typically more pronounced increase in left ventricular end-systolic volume (LVESV) than in left ventricular end-diastolic volume (LVEDV) with airway resistance is shown for the baseline (thin line) and for the $3 \mathrm{~L}$ simulations (heavy line). The largest decrease in LVESV and LVEDV was obtained with the $3 \mathrm{~L}$ simulation (similar changes in simulated right ventricular end-systolic and end-diastolic volumes are not shown for clarity).

a baseline value of $0.0026 \mathrm{mmHg} \cdot \mathrm{s} / \mathrm{mL}$ at $-5.4 \mathrm{mmHg}$ Pth to $0.1626 \mathrm{mmHg} \cdot \mathrm{s} / \mathrm{mL}$ at $-52.4 \mathrm{mmHg}$ Pth. Baroreflex control was not included in the simulations. Simulated curves of left ventricular (LV) and right ventricular (RV) volumes were automatically generated and end-systolic, end-diastolic, and stroke volumes were calculated for the entire range and compared to several OSB studies reporting LVSV and, in most cases, Pth or airway pressure measurements.

\section{Results}

Baseline simulation of the inspiratory fall in LVSV by increasing airway resistance in the model showed a progressive, curvilinear reduction in LVSV up to $11 \%$ at $-52 \mathrm{mmHg}$ Pth from the reference value of $76 \mathrm{~mL}$ at $-5.4 \mathrm{mmHg}$ Pth (resting end-expiration) (Figure 1).

These values were comparable to those obtained in healthy subjects by cardiac catheterization during sustained Mueller maneuvers $[3,21]$ and by simulations from a model of experimental inspiratory loading [17].

Table 1 presents data of seven studies with their reported average percent LVSV drop and corresponding intrathoracic

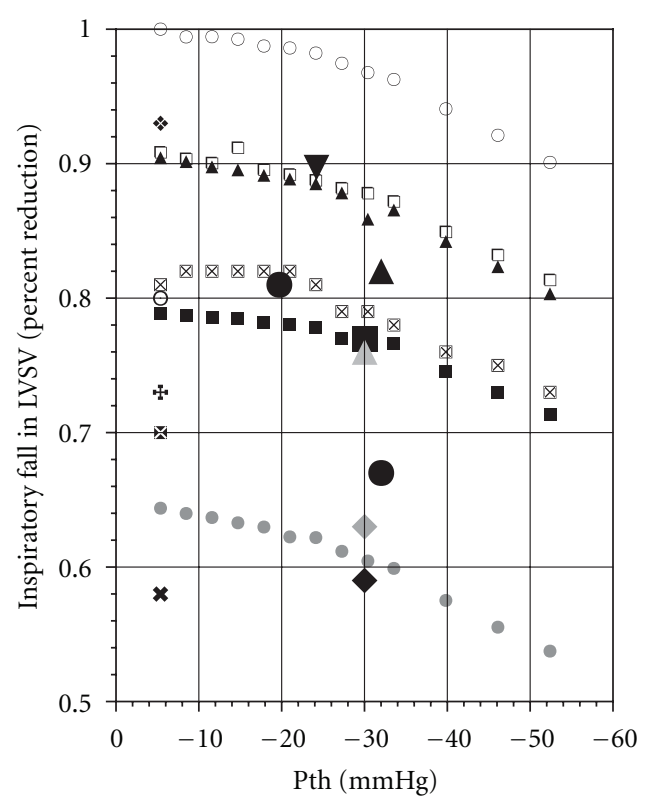

\begin{tabular}{|c|c|}
\hline Sim baseline & Bradley [3] \\
\hline$\square$ Sim LVEDc & $\triangle$ Buda [4] \\
\hline $\boldsymbol{\Delta}$ Sim central volume & $\Delta$ Garpestad [6] \\
\hline$\otimes \operatorname{Sim}$ RVEDc & $>$ Garpestad [7] \\
\hline - $\operatorname{Sim} C v$ & $\odot$ Nelson [26] \\
\hline $\operatorname{Sim} 3 \mathrm{~L}$ & * VanLieshout [24] \\
\hline Stoohs [13] & John [25] \\
\hline Tolle [15] & \& John [25] \\
\hline Hall [8] & $\boldsymbol{X}$ Campbell [22] \\
\hline
\end{tabular}

FIGURE 2: Same simulations as in Figure 1 of the inspiratory fall in left ventricular stroke volume (LVSV) in percent reduction from baseline and compared to data from the literature (Table 1). LVSV decline from patients with obstructive sleep apnea $[6,7,13,15]$ measured during spontaneous breathing, and from patients with congestive heart failure $[3,8]$ and status after cardiac surgery [4] challenged with a Mueller maneuver were substantially below the values from healthy subjects and baseline simulation at comparable Pth (see text).

pressures in patients with OSB. When these clinical data were contrasted with the baseline simulation, they were largely below the full Pth range (Figures 1 and 2).

Parameter modifications intended to fit the higher OSB values for inspiratory fall in LVSV were applied to the model relationship between LVSV and Pth. By increasing 15\% the unstressed volume of the systemic veins (from the baseline value of $2.6 \mathrm{~L}$ to $3.0 \mathrm{~L}$ ), LVSV showed a large drop to $49 \mathrm{~mL}$ at $-5.4 \mathrm{mmHg}$ Pth.

However, when either the venous capacitance parameter doubled, or LV end-diastolic compliance decreased 20\%, or pulmonary central blood volume increased 20\% from their baseline values, the LVSV decrease at $-5.4 \mathrm{mmHg}$ Pth was smaller $(60 \mathrm{~mL}, 69 \mathrm{~mL}$, and $69 \mathrm{~mL}$, respectively). The simulation with a right ventricular end-diastolic compliance decreased in half was very close to the LVSV-Pth relationship of the increased venous capacitance (Figure 1).

The largest LVSV fall reported by Garpestad et al. [6, 7] (Table 1) was closely simulated by the increased parameter of unstressed volume of the systemic veins ( $41 \%$ of inspiratory fall in LVSV at $-30.4 \mathrm{mmHg}$ of Pth) (Figure 2). 
TABLE 1: Upper airway obstruction and changes in left ventricular stroke volume (LVSV) and in left ventricular transmural pressure (PLV $\mathrm{tm})$.

\begin{tabular}{|c|c|c|c|c|}
\hline & & Pes $\mathrm{cm} \mathrm{H}_{2} \mathrm{O}$ & LVSV \% & $\Delta \mathrm{PLV} \mathrm{tm} \mathrm{mmHg}$ \\
\hline \multirow{2}{*}{ Goldman [17] } & \multirow{2}{*}{ Inspiratory loading (normal LV) } & $-52^{\#}$ & -17 & 35 \\
\hline & & $-30^{\#}$ & -3 & 15 \\
\hline Condos et al. [21] & Mueller maneuver (normal LV) & $-50(\mathrm{Paw})$ & -11 & \\
\hline Bradley et al. [3] & Mueller maneuver (normal LV) & -30 & -14 & \\
\hline Stoohs and Guilleminault [13] & OSA (normal LV; NREM period) & $-24.2 \pm 14.8$ & $-10.3 \pm 10.5$ & \\
\hline Shivalkar et al. [12] & OSA (normal LV; awake) & & -8 & \\
\hline Tkacova et al. [14] & OSA (CHF; NREM period)) & $-12.2 \pm 2^{\#}$ (swing) & & 12.8 \\
\hline Bradley et al. [3] & CHF (Mueller maneuver) & -30 & $-32^{*}$ & $7^{*}$ \\
\hline \multirow{2}{*}{ Hall et al. [8] } & \multirow{2}{*}{ CHF (Mueller maneuver) } & $-19.7 \pm 4.5$ & -19 & $7.2 \pm 3.5$ \\
\hline & & $-32.0 \pm 4.2$ & -33 & $11.3 \pm 6.8$ \\
\hline Buda et al. [4] & CABG, Tx (LVEF 43.4\%) (Mueller maneuver) & $-30(\mathrm{Paw})$ & -24 & 25 \\
\hline Tolle et al. [15] & OSA (normal LV; intraapneic) & $-32 \pm 1.3$ & -18 & \\
\hline Garpestad et al. [6] & OSA (normal LV; postapneic) & & $-41^{\S}$ & \\
\hline Garpestad et al. [7] & OSA (normal LV; apnea recovery) & & $-37^{\S}$ & \\
\hline
\end{tabular}

${ }^{*}$ Values estimated from Table 1 and Figure 3 in Bradley et al. [3].

\#Values given in mmHg in Tkacova et al. [14].

§ Pth was not measured; an assumed value of $-30 \mathrm{mmHg}$ was used in Figure 1 based on Stoohs and Guilleminault [13] and Tolle et al. [15].

Pes: esophageal pressure; CABG: coronary artery bypass graft; Tx refers to heart transplant; LVEF: left ventricular ejection fraction; CHF: congestive heart failure; OSA: obstructive sleep apnea; NREM: nonrapid eye movement.

These LVSV simulations showed a downward trend decreasing each about $10 \%$ at the highest negative Pth with a nearly parallel displacement from the baseline LVSV-Pth function, and encompassing most of the OSB data around $30 \mathrm{mmHg}$ Pth.

The five simulations of left ventricular end-diastolic (LVEDV) and end-systolic (LVESV) volumes as a function of Pth showed the typical positive correlation with airway resistance and the overall reduced values when compared to the baseline. The largest reduction in LVEDV and LVESV (about 30\%) was obtained by increasing the unstressed volume of the systemic veins (Figure 1).

\section{Discussion}

A major finding of this study is that the widely described LVSV fall in OSB is larger than that predicted by increasing the negative intrathoracic pressure alone, implying that the airway obstruction component in OSB (with increased vascular transmural pressures and ventricular interdependence) appears to have a less dominant hemodynamic role per se.

Stroke volume simulations relied on a validated computer model of a stepwise increase in airway resistance in healthy subjects [17] as more representative of the typical OSB repetitive intrathoracic pressure oscillations. Baseline maximum inspiratory LVSV decline reached 10\% at $-52 \mathrm{mmHg}$ and compares well to LVSV values obtained in subjects with normal hemodynamics by thermodilution cardiac output, [21] and by Doppler echocardiography, [3] during a single, sustained Mueller maneuver (Table 1).

Although diverse parameter combinations could have been arranged for fitting the clinical data, changes in $\mathrm{LV}$ and RV end-diastolic compliances, unstressed volume and compliance of systemic veins and unstressed volume of the pulmonary circulation were selected as the best approximation to OSB physiopathology. $[1-5,9,10,16,22]$ Since the association of OSB and cardiovascular impairment is multifactorial (hypertension, LV hypertrophy systolic and diastolic dysfunction, increased systemic venous return, volume expansion, heart failure), simulation using isolated factors could help estimate their relative contribution to the LVSV fall.

Simulated LVSV decline from baseline by using either reduced LV end-diastolic compliance or increased central blood volume (Figures 1 and 2) fits a $-10.3 \%$ LVSV fall estimated by electrical impedance during NREM sleep in five subjects with severe OSB without cardiovascular pathology by Stoohs and Guilleminault [13] (Table 1). Although they attributed the LVSV change to a rather modest $-24.2 \mathrm{cmH}_{2} \mathrm{O}$ Pth nadir, the simulation suggests additional ventricular dysfunction and pulmonary vascular involvement. This simulation level is also closer to the finding by Shivalkar et al. [12] of a LVSV decline of $-8 \%$ (compared to an overweight control group) in awake OSB patients with biventricular dysfunction; LVSV was obtained by Doppler echocardiography during resting ventilation at a presumably small Pth (Pth was not measured). Similarly, a low Pth swing of $12.2 \mathrm{mmHg}$ played a minor role in the increased afterload (systolic transmural pressure) during non-REM sleep in CHF patients with OSB [14].

Further reduction in stroke volume was obtained by simulating either increased systemic venous compliance or reduced RV end-diastolic compliance. This trend was within the range of data reported during sustained respiratory efforts (Mueller maneuver) in awake patients with congestive heart failure, $[3,8]$ and with chronic airway obstruction who underwent previous coronary artery bypass graft or heart transplant surgery [4]. 
These studies pointed to an increased afterload, late effect of preload, RV distension, and systolic dysfunction although they used a nonintermittent high negative intrathoracic pressure. A comparable LVSV decrease during daytime obstructive sleep apneas $\left(\mathrm{SaO}_{2} 89.6 \%\right)$ was found by impedance cardiography in patients with apparent normal ventricular function [15]. It cannot be ruled out that this $-18 \%$ LVSV change (correlated with middiastolic Pth and suggesting a decreased preload) had a component of myocardial dysfunction considering its prevalence in OSB.

Increasing the unstressed volume of the systemic veins parameter to $3.0 \mathrm{~L}$ (default value $2.6 \mathrm{~L}$ ) resulted in a simulated LVSV fall to $-39 \%$ from baseline (at $-30.3 \mathrm{mmHg}$ Pth). This value compares well with data $[6,7]$ (Table 1 and Figure 2) from two series of severe OSB patients without history of cardiac disease $\left(\mathrm{SaO}_{2}<82 \%\right)$ during the apnea termination period of non-REM sleep (Pth was not recorded and LVSV was calculated from ESV and EDV obtained by radionuclide ventriculography). This large LVSV decline was explained by an increased postapneic LVESV (more than double that in early apnea) and LVEDV unchanged, reflecting an increased afterload.

This finding appears in contrast to the $3 \mathrm{~L}$ simulation where augmented LVESV with incremental obstruction only reached $11 \%$ (at $-30 \mathrm{mmHg}$ Pth) whereas LVEDV dropped 31\% below baseline suggesting the well-known LVSV sensitivity to systemic venous intravascular volume and compliance $[22,23]$.

In this regard, several reports described the effect of orthostatic redistribution of blood by venous pooling during head-up tilt (HUT) on LVSV at end-expiration; LVSV decreases were $42 \%$, [24] 27\%, [25], and 20\%, [26] from supine to $70^{\circ} \mathrm{HUT}, 45^{\circ} \mathrm{HUT}$, and $30^{\circ} \mathrm{HUT}$, respectively (Figure 2). In the later study, LVESV showed no changes and LVEDV decreased $18 \%$ with HUT, a trend that is in agreement with the $3 \mathrm{~L}$ and $\mathrm{Cv}$ simulations. Although this is consistent with the model capability to investigate the LVSV response to orthostatic unloading, [27] whether it implies that a volume shift may be operating in OSB at high negative Pth is unclear. Arguably, since only a small increase of $0.4 \mathrm{~L}$ in the systemic veins unstressed volume was enough to simulate a large LVSV change, this factor could have been present in the severe OSB studies by Garpestad et al. $[6,7]$

Decreased LVED and RVED compliances described in cases with reduced myocardial distensibility (CHF, volume overload with diastolic flattening of the interventricular septum and increased pulmonary central blood volume) were applied in simulations that appear very similar to the left ventricular OSB data (Table) with and without overt CHF. The blunted effect of increased myocardial stiffness on LVSV fall (only 7\%) - as in the heart failure with preserved ejection fraction during HUT [25] — was well approximated by simulating a reduced LVED compliance (Figure 2).

The selected parameter adjustments provided acceptable boundaries of the model to the clinical data range of LVSV fall. A more precise parameter combination would have been limited by the spread in LVSV reduction at a similar Pth due to different patient cohorts and type of measurements. In addition, there is a dearth of OSB studies measuring LVSVPth dependency and intracavitary transmural pressures at increased levels of airway obstruction. Considering the similarity of the LVSV fall between postural unloading data and the simulations by increasing intravascular volume and compliance of the systemic veins compartment, it is tempting to speculate if Pth related volume shifts could occur in OSB as a slow fluid migration into the interstitium. This volume does not need to be necessarily large, perhaps in the order of $500 \mathrm{~mL}$ for HUT, [27] that is comparable to the simulation of $400 \mathrm{~mL}$ increase in unstressed volume of systemic veins. Further, a qualitatively equivalent effect would be the reduced RV preload observed during sustained negative Pth by collapsing venous thoracic inlets [21]. Although simulations based on these assumptions appear compatible with clinical data showing $>30 \%$ LVSV decline, a more likely scenario in OSB would be fluid overload with a lesser LVSV impact.

In summary, a decreasing LVSV-Pth relationship by applying a mathematical model simulation was found similar to reported data from healthy subjects, but much smaller than those described in several series of OSB patients showing a widespread LVSV decline between $10 \%$ to $41 \%$ from baseline and seemingly unrelated to the presence of CHF. The results of the model parameter modification fit the data; however, it exhibits the functional complexity of a multipathway where end-diastolic biventricular compliance, central blood volume, preload, and volume shifts may play a more critical role in depressing LVSV than the level of negative intrathoracic pressure (Table 1).

\section{Disclaimer}

This work entails the analysis of a mathematical model applied to published clinical studies and there were no human subjects involved. The author assumes full responsibility for the authorship. This work is original and has not been published before or submitted for publication.

\section{Conflict of Interests}

There are no conflict of interests to be reported and no financial support.

\section{Acknowledgment}

Expert editing by $\mathrm{K}$. Hudec is gratefully acknowledged.

\section{References}

[1] M. Alchanatis, G. Tourkohoriti, E. N. Kosmas et al., "Evidence for left ventricular dysfunction in patients with obstructive sleep apnoea syndrome," European Respiratory Journal, vol. 20, no. 5, pp. 1239-1245, 2002.

[2] T. D. Bradley and J. S. Floras, "Obstructive sleep apnoea and its cardiovascular consequences," The Lancet, vol. 373, no. 9657, pp. 82-93, 2009.

[3] T. D. Bradley, M. J. Hall, S. I. Ando, and J. S. Floras, "Hemodynamic effects of simulated obstructive apneas in 
humans with and without heart failure," Chest, vol. 119, no. 6, pp. 1827-1835, 2001.

[4] A. J. Buda, M. R. Pinsky, and N. B. Ingels, "Effect of intrathoracic pressure on left ventricular performance," New England Journal of Medicine, vol. 301, no. 9, pp. 453-459, 1979.

[5] K. Devulapally, R. Pongonis, and R. Khayat, "OSA: the new cardiovascular disease: part II: overview of cardiovascular diseases associated with obstructive sleep apnea," Heart Failure Reviews, vol. 14, no. 3, pp. 155-164, 2009.

[6] E. Garpestad, H. Katayama, J. A. Parker et al., "Stroke volume and cardiac output decrease at termination of obstructive apneas," Journal of Applied Physiology, vol. 73, no. 5, pp. 17431748, 1992.

[7] E. Garpestad, J. A. Parker, H. Katayama et al., "Decrease in ventricular stroke volume at apnea termination is independent of oxygen desaturation," Journal of Applied Physiology, vol. 77, no. 4, pp. 1602-1608, 1994.

[8] M. J. Hall, S. I. Ando, J. S. Floras, and T. D. Bradley, "Magnitude and time course of hemodynamic responses to Mueller maneuvers in patients with congestive heart failure," Journal of Applied Physiology, vol. 85, no. 4, pp. 1476-1484, 1998.

[9] Y. Kaneko, J. S. Floras, K. Usui et al., "Cardiovascular effects of continuous positive airway pressure in patients with heart failure and obstructive sleep apnea," New England Journal of Medicine, vol. 348, no. 13, pp. 1233-1241, 2003.

[10] A. Malhotra and J. Loscalzo, "Sleep and cardiovascular disease: an overview," Progress in Cardiovascular Diseases, vol. 51, no. 4, pp. 279-284, 2009.

[11] S. M. Scharf, J. A. Bianco, D. E. Tow, and R. Brown, "The effects of large negative intrathoracic pressure on left ventricular function in patients with coronary artery disease," Circulation, vol. 63, no. 4, pp. 871-875, 1981.

[12] B. Shivalkar, C. Van De Heyning, M. Kerremans et al., "Obstructive sleep apnea syndrome: more insights on structural and functional cardiac alterations, and the effects of treatment with continuous positive airway pressure," Journal of the American College of Cardiology, vol. 47, no. 7, pp. 14331439, 2006.

[13] R. Stoohs and C. Guilleminault, "Cardiovascular changes associated with obstructive sleep apnea syndrome," Journal of Applied Physiology, vol. 72, no. 2, pp. 583-589, 1992.

[14] R. Tkacova, F. Rankin, F. S. Fitzgerald, J. S. Floras, and T. D. Bradley, "Effects of continuous positive airway pressure on obstructive sleep apnea and left ventricular afterload in patients with heart failure," Circulation, vol. 98, no. 21, pp. 2269-2275, 1998.

[15] F. A. Tolle, W. V. Judy, P. L. Yu, and O. N. Markand, "Reduced stroke volume related to pleural pressure in obstructive sleep apnea," Journal of Applied Physiology Respiratory Environmental and Exercise Physiology, vol. 55, no. 6, pp. 1718-1724, 1983.

[16] J. W. Weiss, S. H. Launois, A. Anand, and E. Garpestad, "Cardiovascular morbidity in obstructive sleep apnea," Progress in Cardiovascular Diseases, vol. 41, no. 5, pp. 367-376, 1999.

[17] E. Goldman, "Age-dependent cardiopulmonary interaction during airway obstruction: a simulation model," American Journal of Physiology, vol. 299, no. 5, pp. H1610-H1614, 2010.

[18] R. Mukkamala, "A cardiovascular simulator for research," in USer's Manual and Software Guide, Harvard-MIT Division of Health Sciences and Technology, Massachusetts Institute of Technology, Cambridge, Mass, USA, 2004.

[19] R. Mukkamala and R. J. Cohen, "A forward model-based validation of cardiovascular system identification," American Journal of Physiology, vol. 281, no. 6, pp. H2714-H2730, 2001.
[20] R. Mukkamala, G. B. Moody, and R. G. Mark, "Introduction of computational models to PhysioNet," Computing in Cardiology, vol. 28, pp. 77-80, 2001.

[21] W. R. Condos, R. D. Latham, S. D. Hoadley, and A. Pasipoularides, "Hemodynamics of the Mueller maneuver in man: right and left heart micromanometry and Doppler echocardiography," Circulation, vol. 76, no. 5, pp. 1020-1028, 1987.

[22] K. Campbell, M. Zeglen, T. Kagehiro, and H. Rigas, "A pulsatile cardiovascular computer model for teaching heartblood vessel interaction," Physiologist, vol. 25, no. 3, pp. 155$162,1982$.

[23] F. M. Melchior, R. S. Srinivasan, and J. B. Charles, "Mathematical modeling of human cardiovascular system for simulation of orthostatic response," American Journal of Physiology, vol. 262, no. 6, pp. H1920-H1933, 1992.

[24] J. J. Van Lieshout, M. P. M. Harms, F. Pott, M. Jenstrup, and N. H. Secher, "Stroke volume of the heart and thoracic fluid content during head-up and head-down tilt in humans," Acta Anaesthesiologica Scandinavica, vol. 49, no. 9, pp. 1287-1292, 2005.

[25] J. M. John, M. Haykowsky, P. Brubaker, K. Stewart, and D. W. Kitzman, "Decreased left ventricular distensibility in response to postural change in older patients with heart failure and preserved ejection fraction," American Journal of Physiology, vol. 299, no. 3, pp. H883-H889, 2010.

[26] M. D. Nelson, L. A. Altamirano-Diaz, S. R. Petersen et al., "Left ventricular systolic and diastolic function during tilttable positioning and passive heat stress in humans," American Journal of Physiology, vol. 301, no. 2, pp. H599-H608, 2011.

[27] T. Heldt, E. B. Shim, R. D. Kamm, R. G. Mark, and Massachusetts, "Computational modeling of cardiovascular response to orthostatic stress," Journal of Applied Physiology, vol. 92, no. 3, pp. 1239-1254, 2002. 


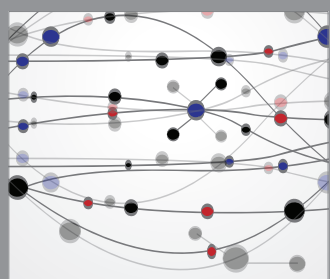

The Scientific World Journal
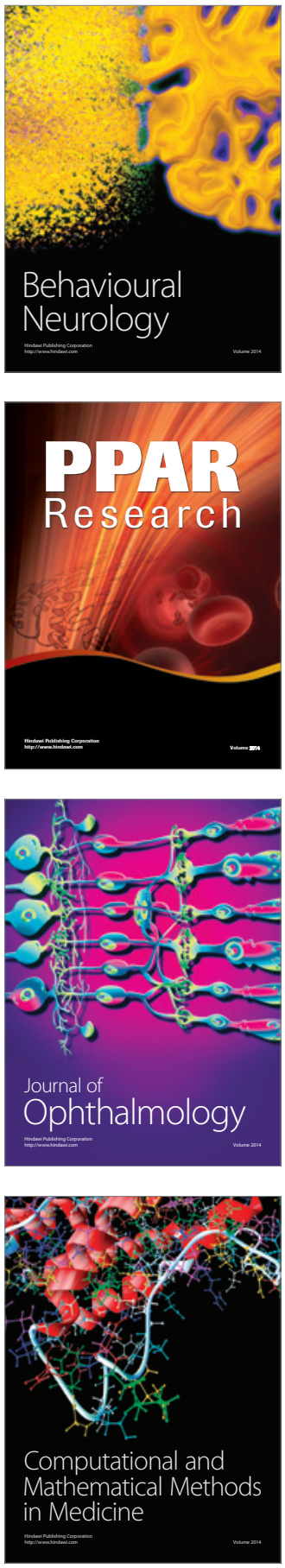

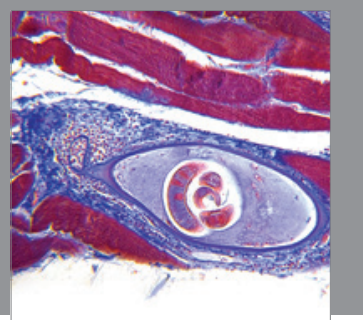

Gastroenterology

Research and Practice
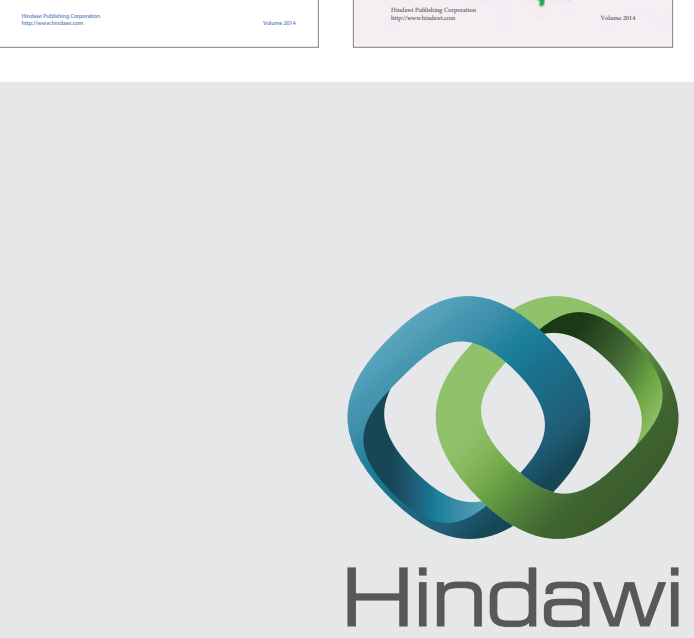

Submit your manuscripts at

http://www.hindawi.com
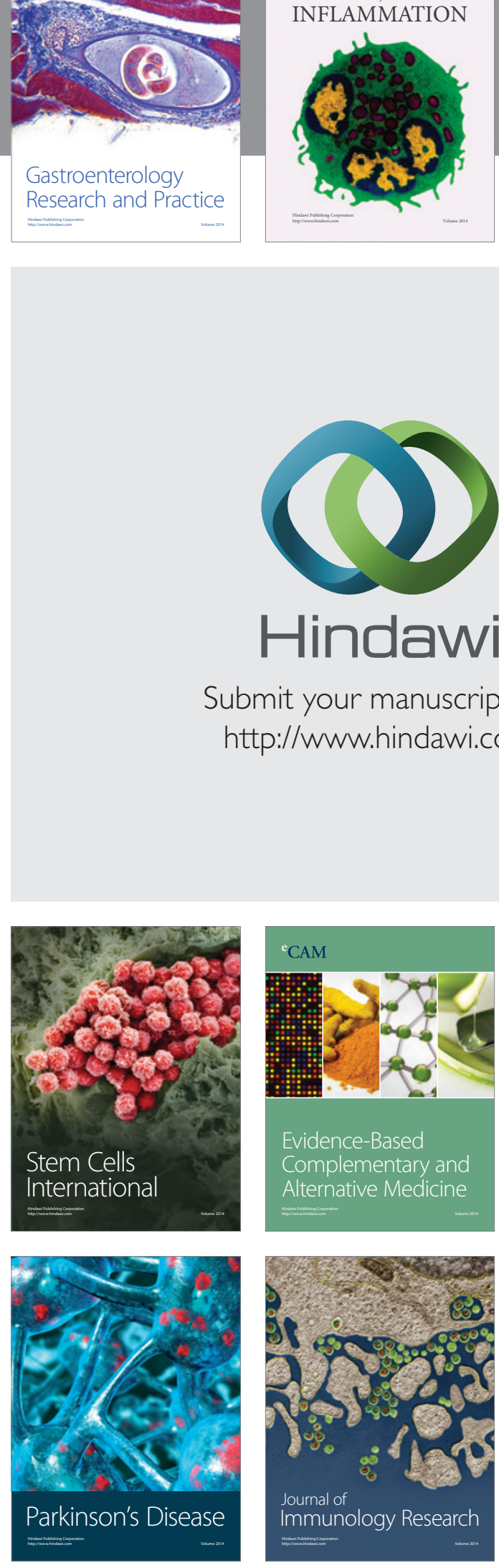

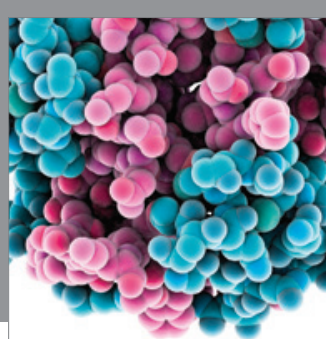

Diabetes Research
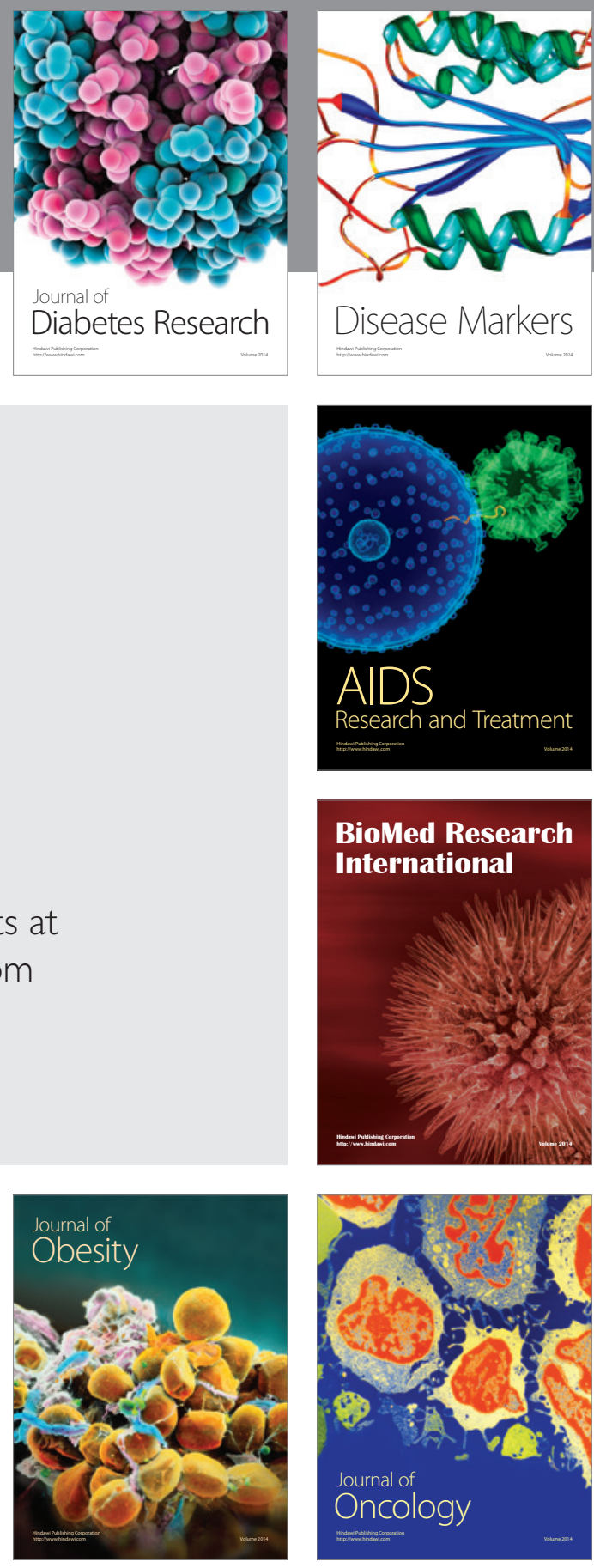

Disease Markers

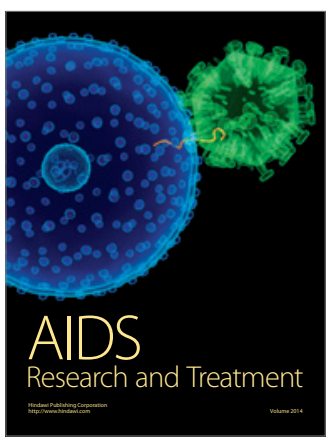

BioMed Research

International
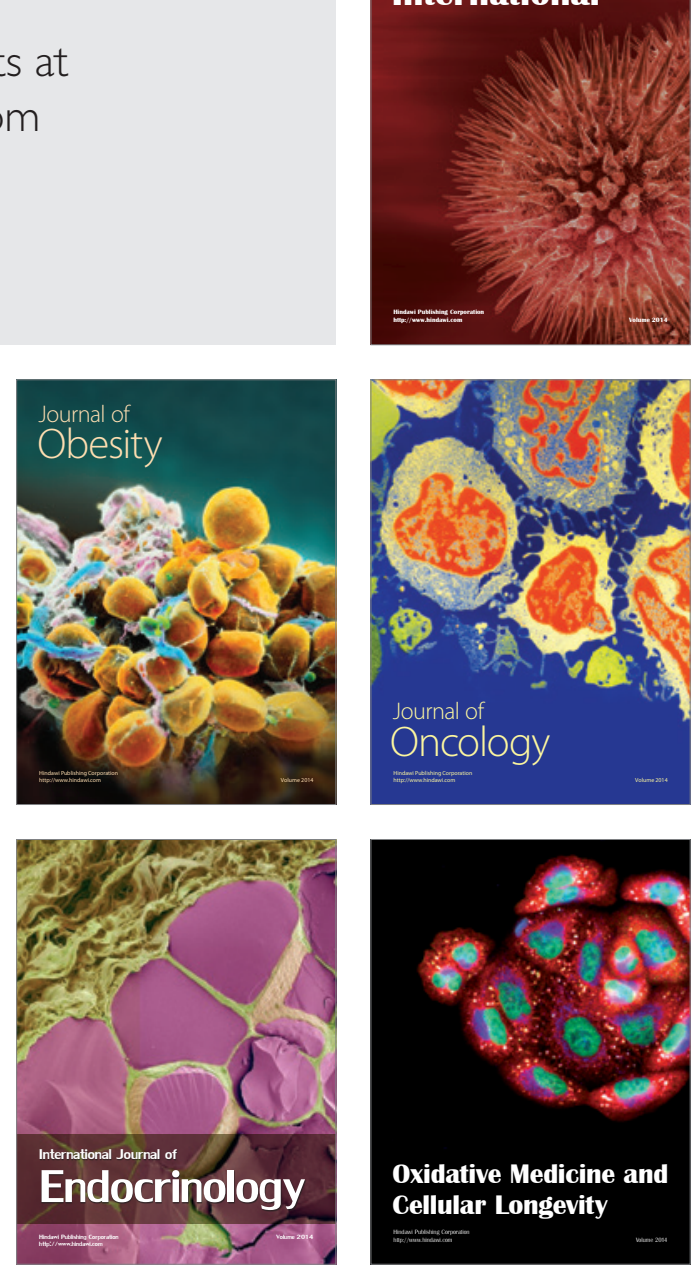